\title{
Cerebrovascular response to continuous cold perfusion and hypothermic circulatory arrest
}

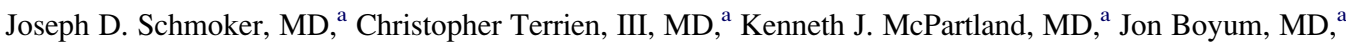 \\ George C. Wellman, PhD, ${ }^{\mathrm{b}}$ Lucy Trombley, MS, ${ }^{\mathrm{a}}$ and John Kinne, BS, CCP ${ }^{\mathrm{a}}$
}

\begin{abstract}
Objective: Clinical and laboratory studies have documented changes in cerebrovascular resistance after hypothermic circulatory arrest, both with and without adjunctive cerebral perfusion modalities. This study was designed to clarify whether these changes are due to cerebral edema, resistance vessel abnormalities, or alterations in the cerebral microcirculation.
\end{abstract}

\begin{abstract}
Methods: Four mature swine underwent hypothermic circulatory arrest for 60 minutes, and 7 mature swine underwent cold cerebral perfusion for 60 minutes to simulate antegrade selective perfusion. All were rewarmed and weaned from cardiopulmonary bypass. Pial vascular diameter and reactivity were measured in vivo through a cranial window and ex vivo in an organ chamber; cerebral microvascular endothelium was studied in culture for release of vasoactive mediators. Cerebral water content was recorded.
\end{abstract}

Results: Cold perfusion caused pial arteriole and venule constriction, whereas hypothermic circulatory arrest alone caused pial arteriole and venule dilatation. Cold perfusion caused a temporal loss of endothelium-dependent vasodilatation, most notably to bradykinin. Hypothermic circulatory arrest caused a loss of nitric oxide-mediated endothelium-dependent vasodilatation. Endothelium-independent vasoreactivity remained intact in both groups. Endothelial cells from the cold group had a vasoconstrictive secretory phenotype, whereas endothelial cells from the hypothermic circulatory arrest group had a vasodilatory phenotype. Cerebral water content was the same in both groups.

Conclusion: The increase in cerebrovascular resistance observed after cold cerebral perfusion is caused by resistance vessel constriction and may be promoted by an altered microcirculation. Hypothermic circulatory arrest alone is associated with endothelium-dependent vasoparesis. Both could contribute to cerebral injury in the early hours after operation.

Neurologic complication after hypothermic circulatory arrest (HCA) occurs from inadequate substrate delivery with ongoing substrate metabolism. ${ }^{1,2}$ Selective cold cerebral perfusion was developed to prolong the safe period of HCA by providing nutritive blood flow in the setting of continuing cerebral metabolism. Continuous cold perfusion, however, is associated with elevated cerebral vascular resistance after cardiopulmonary bypass (CPB), ${ }^{1,3,4}$ which could contribute to neurologic injury in the vulnerable period early after cardiovascular operation. HCA alone has a variable effect on cerebral vascular resistance after separation from $\mathrm{CPB}^{5-8}$ It is unclear whether the increase in cerebral vascular resistance after cold perfusion is related to cerebral edema, arteriole constriction, or an abnormality in the cerebral microcirculation.

\footnotetext{
From the Departments of Surgery ${ }^{\mathrm{a}}$ and Pharmacology, ${ }^{\mathrm{b}}$ The University of Vermont College of Medicine, Burlington, Vt.

This work was partially supported by the Totman Medical Research Trust Fund.

Received for publication June 10, 2008; revisions received July 25, 2008; accepted for publication Aug 13, 2008.

Address for reprints: Joseph D. Schmoker, MD, Division of Cardiothoracic Surgery, Fletcher Allen Health Care, Fletcher 454, 111 Colchester Ave, Burlington, VT 05401 (E-mail: joseph.schmoker@vtmednet.org).

J Thorac Cardiovasc Surg 2009;137:459-64

$0022-5223 / \$ 36.00$

Copyright (c) 2009 by The American Association for Thoracic Surgery

doi:10.1016/j.jtcvs.2008.08.022
}

This study was designed to directly measure the effect of both continuous cold cerebral perfusion and HCA alone on cerebral water content, the cerebral resistance vessel diameter and reactivity, and the secretory phenotype of the cerebral microcirculation. It was hypothesized that continuous cold perfusion is associated with a cerebral vasoconstrictive phenotype when compared with HCA alone. To test this hypothesis, cerebral cortical water content, the in vivo response of pial arterioles and their in vitro reactivity in an organ chamber, and the secretory profile of the cerebral microvascular endothelium were measured during and after continuous cold perfusion and HCA.

\section{MATERIALS AND METHODS \\ Animal Preparation}

Mature swine (35-65 kg) were premedicated with ketamine $(10 \mathrm{mg} / \mathrm{kg}$ intramuscularly), and anesthesia was induced with $4 \%$ isoflurane. Animals were then intubated orally and ventilated with a mixture of room air and $0.5 \%$ to $2.0 \%$ isoflurane. Ventilation was adjusted to maintain normocapnia with an end-tidal $\mathrm{CO}_{2}$ analyzer (Datex $223 \mathrm{CO}_{2}$ Monitor, PuritanBennett Corp, Wilmington, Mass) and arterial blood gas monitor (2500 Co-oximeter, Ciba-Corning Diagnostics Corporation, Medfield, Mass) The $\mathrm{PaO}_{2}$ was maintained between 80 and $100 \mathrm{~mm} \mathrm{Hg}$. Core body temperature was monitored with a thermistor-tipped vascular catheter $(7.5 \mathrm{~F}$, American Edwards Labs, Irvine, Calif) and a nasopharyngeal temperature probe. A servomechanically controlled heating pad was used to maintain normothermia before and after CPB. The femoral vessels were cannulated for blood sampling, fluid administration, and mean arterial pressure 


$$
\begin{aligned}
& \text { Abbreviations and Acronyms } \\
& \text { Ach }=\text { acetylcholine } \\
& \text { CPB }=\text { cardiopulmonary bypass } \\
& \text { CSF }=\text { cerebrospinal fluid } \\
& \text { DMEM } \\
& \text { HCA Dulbecco modified Eagle medium } \\
& \text { MAP }=\text { hypothermic circulatory arrest } \\
& \text { NO }=\text { nitric oxide } \\
& \text { PSS }=\text { physiologic saline solution }
\end{aligned}
$$

(MAP) and central venous pressure monitoring. Lactated Ringer's solution was administered to compensate for evaporative losses and third spacing. The rate was adjusted to maintain urine output greater than $0.5 \mathrm{~mL} / \mathrm{kg} / \mathrm{h}$ and MAP between 55 and $70 \mathrm{~mm} \mathrm{Hg}$. A mini-laparotomy was performed for bladder catheterization for measurement of urine output.

The animals were placed in the prone position with their heads stabilized on a padded frame. A T-shaped scalp incision was performed to expose the skull for placement of a $10-\mathrm{mm}$ closed cranial window for visualization of pial vessels. ${ }^{9}$ The window was placed over the left parietal cortex and equipped with 2 openings to serve as ports for infusion of vasoactive drugs and artificial cerebrospinal fluid (CSF; $\mathrm{Na}^{+} 150 \mathrm{mEq} / \mathrm{L}, \mathrm{K}^{+} 3 \mathrm{mEq} / \mathrm{L}, \mathrm{Ca}^{2+} 2.5$ $\mathrm{mEq} / \mathrm{L}, \mathrm{Mg}^{2+} 1.2 \mathrm{mEq} / \mathrm{L}, \mathrm{Cl}^{-} 132 \mathrm{mEq} / \mathrm{L}$, glucose $3.7 \mathrm{mmol} / \mathrm{L}$, urea 6 $\mathrm{mmol} / \mathrm{L}$, and $\mathrm{HCO}_{3}^{-} 25 \mathrm{mEq} / \mathrm{L}$ ). The artificial CSF was equilibrated with gas containing $6.5 \%$ oxygen, $6.0 \%$ carbon dioxide, and $87.5 \%$ nitrogen at $37^{\circ} \mathrm{C}$ to give gas tensions and $\mathrm{pH}$ in the normal range for CSF.

Access for CPB was performed through a left thoracotomy. Heparin (300 $\mathrm{U} / \mathrm{kg}$ ) was administered, and the ascending aorta was cannulated with a $16 \mathrm{~F}$ arterial cannula (CR Bard Inc, Haverhill, Mass). The right atrial appendage was cannulated with a $24 \mathrm{~F}$ right-angle cannula (Edwards Lifescience LLC, Irvine, Calif). The $\mathrm{CPB}$ circuitry included a membrane oxygenator, a cardiotomy reservoir, and an arterial filter (Medtronic, Minneapolis, Minn). CPB flow was initiated at $100 \mathrm{~mL} / \mathrm{kg} / \mathrm{min}$ and adjusted to maintain MAP between 55 and $60 \mathrm{~mm} \mathrm{Hg}$. The alpha-stat $\mathrm{pH}$ management strategy was used. The degree of anticoagulation was monitored with activated clotting times.

\section{In Vivo Diameter Studies}

Two to four pial arterioles and venules (60-250 $\mu \mathrm{m}$ in diameter) were selected for observation over the left hemisphere at $40 \times$ magnification using an OpMi 1 stereomicroscope (Carl Zeiss, Oberkochen, West Germany). Vessel diameters were measured with an image-splitting eyepiece (Vicker's, AEI Imaging Splitting Eyepiece, Woburn, Mass). After recording baseline diameter measurements, $5 \mathrm{~mL}$ of $10^{-7} \mathrm{~mol} / \mathrm{L}$ acetylcholine (Ach) solution (Sigma Chemical, St Louis, Mo) was infused under the window for assessment of endothelium-dependent vasodilatation. Ach acts on the endothelium via muscarinic receptor-mediated release of nitric oxide (NO).

Concentrations of $10^{-7}$ to $10^{-8} \mathrm{~mol} / \mathrm{L}$ cause dilatation of pial arterioles to $110 \%$ to $120 \%$ of baseline. ${ }^{10}$ Higher concentrations of Ach act directly on the smooth muscle cell to cause contraction, overriding the endothelial cell mediated vasodilatory response. The direct smooth muscle effect can also occur when the receptor-mediated endothelial cell response is dysfunctional. After completion of diameter measurements, $5 \mathrm{~mL}$ of artificial CSF was infused to remove the Ach and allow vessels to return to their original diameters. Five milliliters of $10^{-7} \mathrm{~mol} / \mathrm{L}$ sodium nitroprusside (Sigma Chemical, St Louis, Mo) was then infused to assess endothelium-independent vasodilatation, followed by washout with artificial CSF.

\section{Experimental Protocol}

After completion of the skull preparation, the animals were left undisturbed for 30 minutes before performing baseline measurements. Animals were then cooled for 30 minutes on $\mathrm{CPB}$ to $18^{\circ} \mathrm{C}$ and randomized to either COLD perfusion $(n=7)$, consisting of an additional 60 minutes of perfusion at $18^{\circ} \mathrm{C}$, or 60 minutes of HCA $(n=4)$. All animals underwent aortic crossclamping and received $300 \mathrm{~mL}$ of cold crystalloid cardioplegia, followed by placement of an ice pack on the heart. After the period of cold perfusion or $\mathrm{HCA}$, animals were rewarmed to $37^{\circ} \mathrm{C}$ over 60 minutes, separated from $\mathrm{CPB}$, and allowed to perfuse normally for 60 minutes before sacrifice. Pial vessel measurements were taken at baseline, after 90 minutes of cold perfusion (COLD group only), after 60 minutes of rewarming, and 60 minutes after separation from CPB.

The animals were euthanized with a concentrated potassium solution under anesthesia, and brains were removed under sterile conditions. A portion of grey matter from the left hemisphere was placed in cold Hank's balanced salt solution (GIBCO, Grand Island, NY) for isolation of cerebral endothelial cells. A second piece of cortical grey matter was weighed, dried for 12 hours at $80^{\circ} \mathrm{C}$, reweighed, and analyzed for cortical water content [(wet weight-dry weight/wet weight)] $\times 100$. The remaining portion of the left hemisphere was placed in oxygenated cold physiologic saline solution (PSS; $4{ }^{\circ} \mathrm{C}, 95 \% \mathrm{O}_{2}, 5 \% \mathrm{CO}_{2}$ ) and transported to the laboratory for isolation of pial arterioles.

This study was approved by the Institutional Animal Care and Use Committee at the University of Vermont, and all animals were handled in a humane manner in compliance with the "Guide for the Care and Use of Laboratory Animal Resources" developed by the Institute of Laboratory Animal Resources.

\section{In Vitro Diameter Studies}

Pial resistance-size arteries (150-350 $\mu \mathrm{m}$ in diameter) were identified and removed from the left hemisphere under oxygenated cold PSS and cannulated on glass pipettes, mounted in a 5-mL myograph chamber (Living Systems Instruments, Burlington, Vt), and bathed in aerated PSS $(20 \%$ $\mathrm{O}_{2}, 5 \% \mathrm{CO}_{2}, 75 \% \mathrm{~N}_{2}$ ) at $37^{\circ} \mathrm{C}$ and $\mathrm{pH}$ 7.4. Diameters were measured with video edge detection equipment and recorded with data acquisition software (DI-700 with WinDaq waveform recording software, Dataq Instruments; Akron, Ohio). The vessels were pressurized to $20 \mathrm{~mm} \mathrm{Hg}$ and allowed to equilibrate in a no-flow state using a burette manometer filled with PSS. Tissue viability was assessed by replacement of $\mathrm{NaCl}$ with 60 $\mathrm{mmol} / \mathrm{L} \mathrm{KCL}$ in PSS

Vessels were discarded if the initial contraction was less than $40 \%$ of resting diameter, indicating nonviability. After washout with PSS and return to resting diameter, intravascular pressure was increased in stepwise fashion to assess for development of myogenic tone, which was defined as a percent decrease relative to the fully dilated diameter at a given intravascular pressure. $^{11}$

Sequential application of increasing concentrations of Ach solution $\left(10^{-9}\right.$ to $10^{-5} \mathrm{~mol} / \mathrm{L}$ in PSS) was performed. A period of 15 minutes was maintained between washouts to allow for equilibration. Vessel diameter was recorded before and after the addition of each solution, and percent change from baseline was recorded. Bradykinin solution $\left(10^{-7} \mathrm{~mol} / \mathrm{L}\right)$ was then applied for further assessment of endothelium-dependent vasodilatation. Sequential application of a series of increasing concentrations of the endothelium-independent vasodilator pinacidil $\left(10^{-8}\right.$ to $10^{-5} \mathrm{~mol} / \mathrm{L}$ in PSS) was then applied and diameter measurements were recorded. Finally, diltiazem solution $\left(5 \times 10^{-5} \mathrm{~mol} / \mathrm{L}\right.$ in PSS, devoid of calcium $)$ was added to establish the fully dilated diameter. Because of varying vessel sizes, diameter changes are expressed as percent change from baseline.

\section{Cell Culture}

Cortical gray matter was minced, placed in $0.01 \%$ type I collagenase (GIBCO) for 15 minutes, and followed by neutralization with (Dulbecco modified Eagle medium) DMEM (GIBCO) and filtration through mesh. An equal volume of DMEM was added, and the suspension was centrifuged at $1500 \mathrm{~g}$ for 10 minutes. The pellet was resuspended in $15 \mathrm{~mL}$ of DMEM (supplemented with $20 \%$ fetal bovine serum, neomycin, and glutamine) 
TABLE 1. Hemodynamic parameters

\begin{tabular}{|c|c|c|c|c|c|c|c|c|c|}
\hline & Groups & $\mathbf{0 ~ h}$ & $P$ & $1.5 \mathrm{~h}$ & $P$ & $2.5 \mathrm{~h}$ & $\boldsymbol{P}$ & $3.5 \mathrm{~h}$ & $P$ \\
\hline \multirow[t]{2}{*}{ MAP } & COLD & $70 \pm 3$ & .55 & $56 \pm 1$ & - & $57 \pm 2$ & .65 & $64 \pm 3$ & .12 \\
\hline & HCA & $67 \pm 3$ & - & - & - & $55 \pm 4$ & - & $56 \pm 2$ & - \\
\hline \multirow[t]{2}{*}{ HR } & COLD & $117 \pm 7$ & .53 & - & - & $120 \pm 16$ & .48 & $115 \pm 8$ & .29 \\
\hline & HCA & $110 \pm 4$ & - & - & - & $109 \pm 6$ & - & $99 \pm 11$ & - \\
\hline \multirow[t]{2}{*}{ CVP } & COLD & $8 \pm 0.5$ & .007 & $6 \pm 1$ & - & $7 \pm 1$ & .69 & $13 \pm 1$ & .02 \\
\hline & HCA & $11 \pm 2$ & - & - & - & $8 \pm 1$ & - & $17 \pm 2$ & - \\
\hline \multirow[t]{2}{*}{ TEMP } & COLD & $37 \pm 0.5$ & .47 & $18 \pm 0.5$ & .39 & $36 \pm 0.5$ & .004 & $35 \pm 0.5$ & .15 \\
\hline & HCA & $37 \pm 0.5$ & - & $17 \pm 0.5$ & - & $38 \pm 0.5$ & - & $36 \pm 0.5$ & - \\
\hline
\end{tabular}

$M A P$, Mean arterial pressure; $H R$, heart rate; $C V P$, central venous pressure; $T E M P$, temperature in degrees centigrade; $C O L D$, continuous cold perfusion; $H C A$, hypothermic circulatory arrest. $0 \mathrm{~h}=$ baseline values before $\mathrm{CPB} ; 1.5 \mathrm{~h}=1.5 \mathrm{~h}$ of continuous cold cerebral perfusion in the COLD group and 30 min of cold perfusion plus 60 min of circulatory arrest in the HCA group; $2.5 \mathrm{~h}=$ completion of rewarming period on $\mathrm{CPB} ; 3.5 \mathrm{~h}=1 \mathrm{~h}$ after separation from CPB.

and plated on $100 \mathrm{~mm}^{2}$ tissue culture dishes (Benton Dickinson, Lincoln Park, NJ). Dishes were placed in a humidified environment at $37^{\circ} \mathrm{C}$ with $5 \% \mathrm{CO}_{2}$. The media was changed after 3 days and every 48 hours thereafter. The cells were passed at confluence and seeded in $25 \mathrm{~cm}^{2}$ tissue culture flasks (Benton Dickinson) and propagated in DMEM. Cells were characterized as endothelium by growth pattern, binding of Bandeiraea simplicifolia lectin (Sigma) and Factor VIII/vWF antibody (DAKO, Carpinteria, Calif), and by the absence of binding of glial fibrillatory acidic protein (Sigma).

Early passage (Passage 2) cells were studied in serum free media. Conditioned media was collected at 2,16 , and 24 hours and stored at $-80^{\circ} \mathrm{C}$, and subsequently assayed for prostacyclin (6-keto-PGF ${ }_{1 \alpha}$ enzyme-linked immunosorbent assay, Caymen Chemical, Ann Arbor, Mich), endothelin (Immunometeric Assay System, Caymen), and NO (Nitrate/Nitrite Fluorometric Assay, Caymen). Results were standardized to cell count and total protein (BCA Protein Assay Reagent, Pierce, Rockford, Ill).

\section{Statistical Analysis}

Data are given as mean values \pm 1 standard error of the mean. Differences between groups were tested using the unpaired Student $t$ test. Differences within groups were tested using the paired Student $t$ test.

\section{RESULTS}

\section{Hemodynamic Parameters}

Hemodynamic parameters and temperature are shown in Table 1. Both the baseline and final central venous pressure were higher in the HCA group. Core body temperature was higher in the HCA group after rewarming, but normalized relative to the COLD group after separation from CPB. The flow rate during 60 minutes of COLD perfusion ranged from 44 to $88 \mathrm{~mL} / \mathrm{kg} / \mathrm{min}$ with a mean of $65 \pm 13 \mathrm{~mL} / \mathrm{kg} /$ min.

There were no meaningful differences between groups in total intravenous fluid volume infused or urine output (total fluid: $8214 \pm 1741 \mathrm{~mL}$ COLD, $6150 \pm 11,224 \mathrm{~mL}$ HCA, $P=.16$; urine output: $2225 \pm 1310 \mathrm{~mL}$ COLD, $1425 \pm$ $1213 \mathrm{~mL}$ HCA, $P=.11$ ). There was no difference between groups in cerebral cortical water content (COLD: $85 \% \pm 12 \%$, HCA: $85 \% \pm 12 \%, P=.97)$.

\section{In Vivo Diameter Studies}

Cold perfusion caused pial venule constriction that persisted after rewarming and restoration of normal perfusion. HCA was associated with venule dilatation after both re- warming and restoration of normal flow (Table 2). Continuous cold perfusion was associated with pial arteriole constriction that persisted after rewarming and separation from CPB. In contrast, pial arteriole dilatation occurred with rewarming and reperfusion after HCA (Table 2).

Endothelium-dependent vasodilatation with application of Ach occurred in both groups at baseline. There was a loss of endothelium-dependent vasodilatation in the COLD group after 90 minutes of cold perfusion. Rewarming was associated with a loss of Ach-induced dilatation in both groups when compared with baseline values $(P=.02$, COLD; $P=.07, \mathrm{HCA})$. The endothelium-dependent vasodilatory response in the COLD group normalized after separation from CPB but was blunted in the HCA group (Table 2). The endothelium-independent vasodilatory response to sodium nitroprusside was preserved in both groups at baseline and during and after separation from CPB (Table 2).

\section{In Vitro Diameter Studies}

Pial arteries in both groups failed to develop myogenic tone in response to serial increases in intraluminal pressure. There was no difference between groups in response to the endothelium-independent vasodilator pinacidil. Vasodilatation in response to application of Ach was not seen in either group. Instead, vasoconstriction occurred in the HCA group at lower concentrations of Ach, indicating endothelial cell dysfunction and unopposed smooth muscle cell activation (Table 3).

There was no meaningful difference in the endotheliumindependent vasodilatory response to diltiazem between groups (COLD: $124 \% \pm 19 \%$, HCA: $126 \% \pm 114 \%$, $P=.88$ ). Application of bradykinin produced vasodilatation after HCA and vasoconstriction after cold perfusion (HCA: $118 \% \pm 18 \%$, COLD: $80 \% \pm 19 \%, P=.02$ ), implying receptor-mediated endothelial cell dysfunction in the COLD group.

\section{Cell Culture}

Microvascular cerebral endothelial cells isolated from animals exposed to continuous cold perfusion secreted more 
TABLE 2. In vivo pial vessel diameter and reactivity

\begin{tabular}{|c|c|c|c|c|c|c|c|c|c|}
\hline & GROUP & $\mathbf{0 ~ h}$ & $\boldsymbol{P}$ & $1.5 \mathrm{~h}$ & $\boldsymbol{P}$ & $2.5 \mathrm{~h}$ & $P$ & $3.5 \mathrm{~h}$ & $\boldsymbol{P}$ \\
\hline \multirow[t]{2}{*}{ Venule Diameter } & COLD & 100 & - & $82 \pm 7$ & - & $81 \pm 6$ & .01 & $66 \pm 5$ & .001 \\
\hline & HCA & 100 & - & - & - & $111 \pm 10$ & - & $123 \pm 15$ & - \\
\hline \multirow[t]{2}{*}{ Arteriole Diameter } & COLD & 100 & - & $87 \pm 5$ & - & $85 \pm 4$ & .05 & $79 \pm 3$ & .09 \\
\hline & $\mathrm{HCA}$ & 100 & - & - & - & $110 \pm 17$ & - & $93 \pm 7$ & - \\
\hline \multirow{2}{*}{$\begin{array}{l}\text { Arteriole Ach } \\
\text { (\% resting value) }\end{array}$} & COLD & $113 \pm 3$ & .78 & $90 \pm 2 *$ & - & $102 \pm 4 \dagger$ & .53 & $121 \pm 7$ & .22 \\
\hline & $\mathrm{HCA}$ & $114 \pm 3$ & - & - & - & $98 \pm 6 \ddagger$ & - & $105 \pm 10$ & - \\
\hline \multirow{2}{*}{$\begin{array}{l}\text { Arteriole SNP } \\
\quad(\% \text { resting value })\end{array}$} & COLD & $108 \pm 1$ & .45 & $112 \pm 3$ & - & $109 \pm 3$ & .74 & $110 \pm 2$ & .70 \\
\hline & $\mathrm{HCA}$ & $110 \pm 2$ & - & & - & $111 \pm 4$ & - & $111 \pm 4$ & - \\
\hline
\end{tabular}

Ach, Acetylcholine reactivity; $S N P$, sodium nitroprusside reactivity; $C O L D$, continuous cold perfusion; $H C A$, hypothermic circulatory arrest. $0 \mathrm{~h}=\mathrm{baseline}$ value before $\mathrm{CPB} ; 1.5$ $\mathrm{h}=1.5 \mathrm{~h}$ of continuous cold cerebral perfusion in the COLD group; $2.5 \mathrm{~h}=$ completion of rewarming period on $\mathrm{CPB} ; 3.5 \mathrm{~h}=1 \mathrm{~h}$ after separation from $\mathrm{CPB} . * P<.001 . \dagger P=.08$. $\ddagger P=.07$ vs baseline.

endothelin and less prostacyclin than animals undergoing HCA. NO was not detected in either group (Table 4).

\section{DISCUSSION}

This study supports previous work that found a decrease in cerebral resistance vessel diameter during continuous cold cerebral perfusion. ${ }^{12}$ This study is unique in the finding that the phenotypic changes occurring in resistance vessels after both continuous cold perfusion and HCA persist after separation from CPB and can be documented in both organ and cell culture. The increase in cerebral vascular resistance after cold perfusion is not caused by cerebral edema but is caused by cerebral arteriole constriction. Intrinsic abnormalities occurred in the endothelial control of resistance vessels and in the vasoactive phenotype of the microcirculation during and after CPB with both cold perfusion and HCA alone. Given the importance of the endothelium in the autocrine and paracrine control of small cerebral resistance vessels, abnormalities in the cellular control of vessel diameter should have a major impact on local and regional substrate delivery.

Continuous cold perfusion caused pial arteriole and venule constriction. Endothelial-mediated arteriole dilatation was impaired during cold perfusion and rewarming but recovered after a period of normal pulsatile perfusion. Others have noted a loss of endothelial-mediated cerebral vasodila- tation during cold perfusion on CPB. ${ }^{12}$ Cerebral arterioles isolated from the cold perfusion animals failed to undergo NO-mediated vasodilatation, implying persistent endothelial cell dysfunction. This was confirmed by a vasoconstrictive response to bradykinin. Bradykinin normally induces vasodilatation in cerebral arterioles by activating endothelial $\mathrm{B}_{2}$ receptors. Bradykinin can produce vasoconstriction by stimulating $B_{1}$ receptors on smooth muscle cells in the presence of dysfunctional or absent endothelium. Bradykinin is also known to cause vasoconstriction in the presence of inducible NO synthase in certain pathologic states. ${ }^{13}$ Future studies could address the cold perfusion-induction of cerebral inducible NO synthase or the induction of cerebrovascular bradykinin receptor re-distribution.

Endothelial cells isolated from the microcirculation of the COLD group showed a constrictive secretory profile. Endothelin secretion was greater in the COLD group when compared with the HCA group. Endothelin is a potent endothelial cell-derived cerebral vasoconstrictor. Pial arteriole endothelial cells have a heightened responsiveness to endothelin relative to systemic arterioles. ${ }^{14}$ Exposure of pial arterioles to endothelin increases their contractile response to hemolyzed blood products, ${ }^{15}$ such as those released during $\mathrm{CPB}$. Substances generated during CPB also induce the synthesis of endothelin, and include thrombin, transforming growth factor- $\beta$, angiotensin II, and arginine vasopressin. ${ }^{16}$

TABLE 3. In vitro pial arteriole reactivity

\begin{tabular}{|c|c|c|c|c|c|c|c|c|c|}
\hline & \multicolumn{3}{|c|}{ Pressure-induced change in diameter } & \multicolumn{3}{|c|}{ Pinacidil } & \multicolumn{3}{|c|}{ Acetylcholine } \\
\hline & COLD & HCA & $\boldsymbol{P}$ & COLD & HCA & $\boldsymbol{P}$ & COLD & HCA & $P$ \\
\hline $20 \mathrm{~mm} \mathrm{Hg}$ & 100 & 100 & - & 100 & 100 & - & 100 & 100 & - \\
\hline $40 \mathrm{~mm} \mathrm{Hg}$ & $110 \pm 2$ & $110 \pm 2$ & 1.0 & & & & & & \\
\hline $60 \mathrm{~mm} \mathrm{Hg}$ & $122 \pm 7$ & $116 \pm 3$ & .55 & & & & & & \\
\hline $80 \mathrm{~mm} \mathrm{Hg}$ & $125 \pm 11$ & $120 \pm 10$ & .77 & & & & & & \\
\hline $10^{-9} \mathrm{~mol} / \mathrm{L}$ & & & & & & & $100 \pm 1$ & $94 \pm 4$ & .10 \\
\hline $10^{-8} \mathrm{~mol} / \mathrm{L}$ & & & & $99 \pm 2$ & $101 \pm 1$ & .32 & $100 \pm 1$ & $88 \pm 6$ & .02 \\
\hline $10^{-7} \mathrm{~mol} / \mathrm{L}$ & & & & $99 \pm 1$ & $102 \pm 1$ & .09 & $98 \pm 4$ & $92 \pm 1$ & .29 \\
\hline $10^{-6} \mathrm{~mol} / \mathrm{L}$ & & & & $103 \pm 1$ & $105 \pm 2$ & .53 & $94 \pm 4$ & $89 \pm 5$ & .41 \\
\hline $10^{-5} \mathrm{~mol} / \mathrm{L}$ & & & & $121 \pm 13$ & $127 \pm 10$ & .78 & $93 \pm 4$ & $88 \pm 3$ & .55 \\
\hline
\end{tabular}

$C O L D$, Continuous cold perfusion; $H C A$, hypothermic circulatory arrest. 
TABLE 4. Prostacyclin and endothelin secretion from cerebral endothelial cells

\begin{tabular}{|c|c|c|c|c|c|c|c|c|c|}
\hline $\begin{array}{c}\text { Time point } \\
\text { (in serum-free media) }\end{array}$ & Group & PGF (pg/10 5 cells) & $P$ & PGF (pg/ $\mu$ g protein) & $P$ & ET $\left(\mathrm{pg} / 10^{5}\right.$ cells $)$ & $P$ & ET (pg/ $\mu \mathrm{g}$ protein) & $P$ \\
\hline \multirow[t]{2}{*}{$2 \mathrm{~h}$} & COLD & $21 \pm 4$ & .53 & $0.13 \pm 0.01$ & .06 & $5.4 \pm 0.8$ & .02 & $0.03 \pm 0.009$ & .003 \\
\hline & $\mathrm{HCA}$ & $17 \pm 5$ & & $0.08 \pm 0.02$ & & $3.1 \pm 0.4$ & & $0.01 \pm 0.002$ & \\
\hline \multirow[t]{2}{*}{$16 \mathrm{~h}$} & COLD & $46 \pm 8$ & .04 & $0.53 \pm 0.2$ & .23 & $13.2 \pm 1$ & .03 & $0.1 \pm 0.03$ & .13 \\
\hline & $\mathrm{HCA}$ & $121 \pm 32$ & & $0.3 \pm 0.08$ & & $10.0 \pm 0.8$ & & $0.06 \pm 0.007$ & \\
\hline \multirow[t]{2}{*}{$24 \mathrm{~h}$} & COLD & $74 \pm 11$ & .03 & $0.59 \pm 0.09$ & .38 & $24.4 \pm 3$ & .12 & $0.2 \pm 0.04$ & .01 \\
\hline & $\mathrm{HCA}$ & $154 \pm 31$ & & $0.81 \pm 0.24$ & & $32.6 \pm 5$ & & $0.08 \pm 0.02$ & \\
\hline
\end{tabular}

$P G F$, Prostacyclin; $E T$, endothelin; $C O L D$, continuous cold perfusion; $H C A$, hypothermic circulatory arrest.

HCA alone is known to induce endothelin-1 mRNA expression in pulmonary arteries and is associated with an increase in the pulmonary vascular resistance. ${ }^{17}$

HCA was not associated with cerebral vasoconstriction. Pial arterioles dilated after rewarming from $\mathrm{HCA}$ and returned to near baseline diameter after 60 minutes of normal pulsatile perfusion. There was, however, a loss of endothelial-mediated vasodilatation in vessels after rewarming, which did not completely normalize after restoration of normal perfusion. Arterioles isolated from HCA animals constricted with application of Ach at doses that normally produce vasodilatation, a finding also noted in the rewarming phase in vivo after HCA. These findings indicate direct unopposed action of Ach on the smooth muscle cell secondary to NO-related endothelial cell dysfunction and are seen in other organ systems after both HCA and hypothermic CPB. ${ }^{18,19}$ This may be related, at least partially, to abnormal endothelial cell-neutrophil interaction $^{20}$ or endothelial cell-platelet interaction. ${ }^{21}$

HCA was associated with a vasodilatory phenotype in cultured microvascular endothelial cells, as evidenced by up-regulation of prostacyclin secretion. Prostacyclin, a potent vasodilator, is released from cerebral endothelial cells and into the CSF during brain ischemia. ${ }^{22,23}$ Prostacyclin release may serve to enhance cerebral blood flow to meet metabolic demand and may, therefore, contribute to the vasodilatation seen in arterioles and venules during rewarming from HCA alone. Similar findings have been noted after resuscitation from hemorrhagic shock. ${ }^{23}$ Vasodilatation after rewarming from HCA could also represent a maladaptive response known as luxury perfusion, a risk factor for embolic stroke as speculated by some authors. ${ }^{5}$

NO was not detected in conditioned media from cerebral endothelial cells in either group, and, as noted, NO-mediated vasodilatation was absent in isolated cerebral arterioles. Others have noted a cerebrovascular NO deficit after $\mathrm{HCA}^{24}$ and NO production by cerebral endothelial cells is impaired after hemorrhage-induced cerebral ischemia. ${ }^{23}$

The direct smooth muscle response to vasodilators remained intact in this study. However, there was a loss of myogenic tone to stepwise application of intraluminal pressure in isolated arteries from both groups. This could signify a loss of pressure autoregulation or a loss of spontaneous vasomotion in cerebral arterioles, which could contribute to abnormalities in local cerebral oxygen delivery. Loss of pressure autoregulation and dysfunctional endothelial cellmediated vasodilatory mechanisms may contribute to low flow states after $\mathrm{HCA}^{7}$ and could predispose patients to neurologic injury in the early hours after operation when hemodynamic instability commonly occurs.

Despite the theoretic clinical advantage of antegrade cerebral perfusion over HCA alone, or retrograde cerebral perfusion, findings of the current study suggest that cold cerebral perfusion may cause intrinsic abnormalities in the cerebral vasculature that could lead to low flow states early after operation. In at least 1 clinical study antegrade cerebral perfusion was associated with worse neurocognitive impairment when compared with $\mathrm{HCA}$ alone. ${ }^{25}$ Others have shown that antegrade perfusion at lower flow rates using mild to moderate hypothermia improves clinical outcome. $3,6,26-28$ Lower flow rates and higher temperatures may limit the vasoconstrictive response and endothelial cell dysfunction seen with high flow rates and profound hypothermia, while still providing nutritive blood flow.

\section{Limitations}

Nonselective antegrade cerebral perfusion was used in this study. The cerebral flow rate is unknown. Higher flows are known to induce vasoconstriction. ${ }^{29}$ Much lower flow rates, however, have also been shown to increase cerebral vascular resistance. ${ }^{7}$ Extrapolating from the adult human, in whom $40 \%$ to $45 \%$ of systemic flow is delivered to the upper body during CPB, it is conceivable that our model delivered upper body flow in the range of 18 to $35 \mathrm{~mL} / \mathrm{kg} / \mathrm{min}$ (mean 26-29 $\mathrm{mL} / \mathrm{kg} / \mathrm{min}$ ) based on our experimental systemic flow rate during cold perfusion. In a recent porcine study, ${ }^{30}$ MAP-dependent flow delivered into the isolated aortic arch was $16 \mathrm{~mL} / \mathrm{kg} / \mathrm{min}$ at a MAP of $50 \mathrm{~mm} \mathrm{Hg}$ and $34 \mathrm{~mL} / \mathrm{kg} / \mathrm{min}$ at a MAP of $70 \mathrm{~mm} \mathrm{Hg}$. It is reasonable to presume that nonselective flow through the common brachiocephalic trunk in our study (mean MAP 56 mm Hg during COLD perfusion) was in the lower range of these flows, making them clinically relevant.

Prolonged cooling before circulatory arrest and antegrade perfusion is often performed to obtain isoelectric electroencephalogram in anticipation of long arrest times. Systemic cooling times are often in excess of 50 minutes, at perfusate 
temperatures of $15^{\circ} \mathrm{C}$ to $18^{\circ} \mathrm{C}$. The systemic cooling time in this study of 30 minutes, followed by 60 minutes of continuous flow, will fall into perfusion ranges used clinically, most commonly during total arch replacement. These data, however, may not have relevance to shorter periods of cold perfusion, such as used in hemiarch replacement. Finally, it would be unwise to extrapolate these data to pediatric patients, because both mature animals and the $\alpha$-stat $\mathrm{pH}$ management strategy were used in this study.

\section{CONCLUSIONS}

This work shows that the increase in cerebrovascular resistance seen clinically after cold antegrade cerebral perfusion is secondary to direct cerebral resistance vessel constriction and suggests that the increase in resistance is associated with an endothelial cell vasoconstrictive phenotype in both the resistance vessels and the microcirculation. The increase in cerebrovascular resistance seen in some clinical studies after HCA alone may not be directly due to resistance vessel constriction but may be related to abnormal autoregulation from endothelial cell dysfunction of NO-mediated vasodilatation, and this may be driven by ischemia. Both modalities could place the cerebral vasculature at risk for inappropriate vasoconstriction early after operation in the setting of unopposed vasoconstrictors released during CPB.

\section{References}

1. Mezrow CK, Gandsas A, Sadeghi AM, et al. Metabolic correlates of neurologic and behavioral injury after prolonged hypothermic circulatory arrest. $J$ Thorac Cardiovasc Surg. 1995;109:959-75.

2. Ehrlich MP, McCullough JN, Zhang N, et al. Effect of hypothermia on cerebral blood flow and metabolism in the pig. Ann Thorac Surg. 2002;73:191-7.

3. Abdul-Khaliq H, Uhlig R, Böttcher W, Ewert P, Alexi-Meskishvili V, Lange PE. Factors influencing the change in cerebral hemodynamics in pediatric patients during and after corrective cardiac surgery of congenital heart diseases by means of full-flow cardiopulmonary bypass. Perfusion. 2002;17:179-85.

4. Hoffman GM, Stuth EA, Jaquiss RD, et al. Changes in cerebral and somatic oxygenation during stage 1 palliation of hypoplastic left heart syndrome using continuous regional cerebral perfusion. J Thorac Cardiovasc Surg. 2004;127:223-33.

5. Mezrow CK, Gandsas A, Sadeghi AM, et al. Evaluation of cerebral metabolism and quantitative electroencephalography after circulatory arrest and low-flow cardiopulmonary bypass at different temperatures. J Thorac Cardiovasc Surg. 1994; 107:1006-19.

6. Jonassen AE, Quaegebeur JM, Young WL. Cerebral blood flow velocity in pediatric patients is reduced after cardiopulmonary bypass with profound hypothermia. J Thorac Cardiovasc Surg. 1995;110:934-43.

7. O'Hare B, Bissonnette B, Bohn D, Cox P, Williams W. Persistent low cerebral blood flow velocity following profound hypothermic circulatory arrest in infants. Can J Anaesth. 1995;42:964-71.

8. Greeley WJ, Ungerleider RM, Kern FH, et al. Effects of cardiopulmonary bypass on cerebral blood flow in neonates, infants, and children. Circulation. 1989;80: 1209-15.
9. Levasseur JE, Wei EP, Paper AJ, et al. Detailed description of a cranial window technique for acute and chronic experiments. Stroke. 1975;6:308-17.

10. Schmoker JD, Shackford SR, Zhuang J. The effect of lesion volume on cerebral vasomotor tone after focal brain injury and shock. $J$ Neurotrauma. 1996;13:67-78.

11. Ishiguro M, Puryear CB, Bisson E, et al. Enhanced myogenic tone in cerebral arteries from a rabbit model of subarachnoid hemorrhage. Am J Physiol Heart Circ Physiol. 2002;283:H2217-25.

12. Wagerle LC, Russo P, Dahdah NS, et al. Endothelial dysfunction in cerebral microcirculation during hypothermic cardiopulmonary bypass in newborn lambs. J Thorac Cardiovasc Surg. 1998;115:1047-54.

13. Fischer LG, Horstman DJ, Hahnenkamp K, Kechner NE, Rich GF. Selective iNOS inhibition attenuates acetylcholine- and bradykinin-induced vasoconstriction in lipopolysaccharide-exposed rat lungs. Anesthesiology. 1999;91: 1724-32.

14. Thorin E, Shatos MA, Shreeve SM, Walters CL, Bevan JA. Human vascular endothelium heterogeneity. A comparative study of cerebral and peripheral cultured vascular endothelial cells. Stroke. 1997;28:375-81.

15. Yakubu MA, Leffler CW. Enhanced pial arteriolar sensitivity to bioactive agents following exposure to endothelin-1. Life Sci. 2000;66:307-16.

16. Inoue A, Yanagisawa M, Takuwa Y, et al. The human preproendothelin-1 gene. J Biol Chem. 1989;264:14954-9.

17. Kirshbom PM, Page SO, Jacobs MT, et al. Cardiopulmonary bypass and circulatory arrest increase endothelin-1 production and receptor expression in the lung. J Thorac Cardiovasc Surg. 1997;113:777-83.

18. Kirshbom PM, Jacobs MT, Tsui SS, et al. Effects of cardiopulmonary bypass and circulatory arrest on endothelium-dependent vasodilatation in the lung. J Thorac Cardiovasc Surg. 1996;111:1248-56.

19. Cooper WA, Duarte IG, Thourani VH, et al. Hypothermic circulatory arrest causes multisystem vascular endothelial dysfunction and apoptosis. Ann Thorac Surg. 2000;69:696-703.

20. Schermerhorn ML, Tofukuji M, Khoury PR, et al. Sialyl lewis ${ }^{\mathrm{X}}$ oligosaccharide preserves cardiopulmonary and endothelial function after hypothermic circulatory arrest in lambs. J Thorac Cardiovasc Surg. 2000;120:230-7.

21. Mime LB, Arnhold S, Fischer JH, et al. Pharmacologic cerebral capillary blood flow improvement after deep hypothermic circulatory arrest: an intravital fluorescence microscopy study in pigs. J Thorac Cardiovasc Surg. 2005;130:670-6.

22. Chen ST, Hsu CY, Hogan EL, et al. Thromboxane, prostacyclin, and leukotrienes in cerebral ischemia. Neurology. 1986;36:466-70.

23. Schmoker JD, Shatos MA, Shackford SR. Cerebral endothelial cell dysfunction after hemorrhagic shock. Surg Forum. 1996;47:581-2.

24. Tsui SS, Kirshbom PM, Davies MJ, et al. Nitric oxide production affects cerebral perfusion and metabolism after deep hypothermic circulatory arrest. Ann Thorac Surg. 1996;61:1699-707.

25. Svensson LG, Nadolny EM, Penney DL, et al. Prospective randomized neurocognitive and S-100 study of hypothermic circulatory arrest, retrograde brain perfusion, and antegrade brain perfusion for aortic arch operations. Ann Thorac Surg. 2001;71:1905-12.

26. Ye J, Dai G, Yang L, Jiankang S, Summers R, Deslauriers R. Is deep hypothermia necessary for unilateral antegrade cerebral perfusion during circulatory arrest? A magnetic resonance study in a pig model. Cardiovasc Surg. 2001;9:600-7.

27. DeCampli WM, Schears G, Myung R, et al. Tissue oxygen tension during regional low-flow perfusion in neonates. J Thorac Cardiovasc Surg. 2003;125:472-80.

28. Cook RC, Gao M, Macnab AJ, Fedoruk LM, Day N, Janusz MT. Aortic arch reconstruction: safety of moderate hypothermia and antegrade cerebral perfusion during systemic circulatory arrest. J Card Surg. 2006;21:158-64.

29. Watanabe T, Oshikiri N, Kiyoshige I, et al. Optimal blood flow for cooled brain at $20^{\circ}$ C. Ann Thorac Surg. 1999;68:864-9.

30. Halstead JC, Meier M, Wurm M, et al. Optimizing selective cerebral perfusion: Deleterious effects of high perfusion pressures. J Thorac Cardiovasc Surg. 2008;135:784-91. 